\title{
Diversity issues in Nigeria's healthcare sector: implications on organizational commitment. A cross-sectional study [version
}

\section{1; peer review: 2 approved with reservations]}

\author{
Ayodotun Stephen Ibidunni (D1, Tomike Olawande2, Maxwell Olokundun(iD1, \\ Charles Iruonagbe ${ }^{2}$, Iyanu Adelekan ${ }^{1}$ \\ ${ }^{1}$ Department of Business Management, Covenant University, Ota, Ogun, 112242, Nigeria \\ ${ }^{2}$ Department of Sociology, Covenant University, Ota, Ogun, 112242, Nigeria
}

V1 First published: 12 Jun 2019, 8:852

https://doi.org/10.12688/f1000research.19350.1

Latest published: 12 Jun 2019, 8:852

https://doi.org/10.12688/f1000research.19350.1

\section{Abstract}

Background: Workplace diversity is increasingly gaining the attention of healthcare organizations, especially in developing countries like Nigeria. However, little is understood from existing literature about how workforce diversity affects employees' satisfaction and organisational commitment in the workplace. Consequently, this paper showed the direct and mediating relationships between diversity of workforce, job satisfaction and employee commitment to the organization.

Methods: Copies of the structured questionnaire have been given to 133 public healthcare employees in Nigeria's Ministry of Health in Lagos state. Statistical analysis for the study included descriptive measures and multi-variate analysis, using structural equation modelling.

Results: Outcomes from statistical analysis supports direct and mediating relationships between the research variables. Gender and ethical diversity had significant influences on job satisfaction at $r=$ $0.35(p<0.05)$ and $r=0.28(p<0.05)$ respectively. The following mediating relationships were also statistically confirmed: job satisfaction related with affective commitment $(r=0.41, p<0.05)$ and normative commitment $(r=0.26, p<0.05)$.

Conclusions: Based on the results of the statistical analysis, the study concludes that there is a relationship between diversity of employees and job satisfaction, diversity of employees and organizational commitment and the influence of work satisfaction on organizational commitment.

Keywords

Workforce diversity, Job satisfaction, Employee commitment, Public healthcare, Diversity management

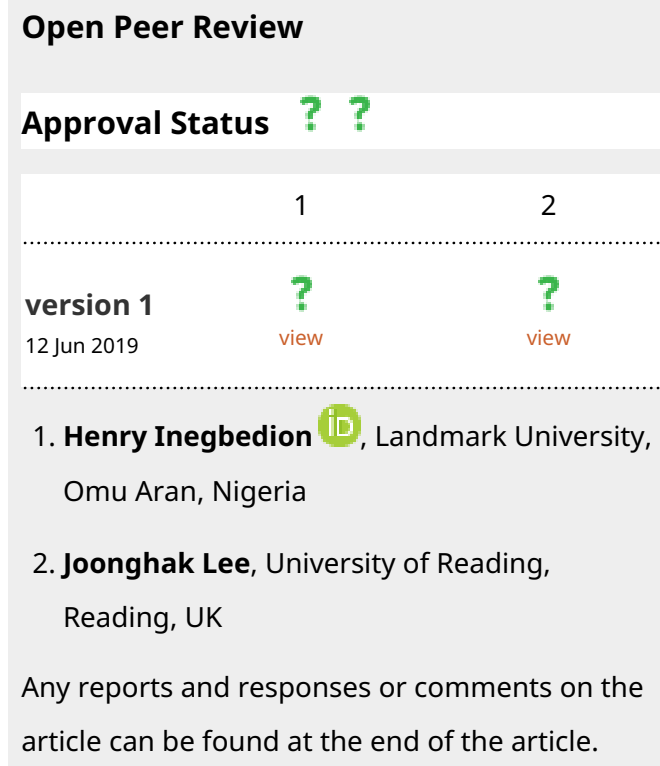

1 2 version 1 12 Jun 2019

$\begin{array}{cc}? & ? \\ \text { view } & \text { view }\end{array}$

1. Henry Inegbedion (DD, Landmark University, Omu Aran, Nigeria

2. Joonghak Lee, University of Reading, Reading, UK

Any reports and responses or comments on the article can be found at the end of the article. 
This article is included in the Sociology of

Health gateway.

Corresponding author: Ayodotun Stephen Ibidunni (ayodotun.ibidunni@covenantuniversity.edu.ng)

Author roles: Ibidunni AS: Conceptualization, Data Curation, Formal Analysis, Methodology, Writing - Original Draft Preparation; Olawande T: Resources, Writing - Review \& Editing; Olokundun M: Methodology, Writing - Original Draft Preparation; Iruonagbe C: Writing - Review \& Editing; Adelekan I: Data Curation, Investigation

Competing interests: No competing interests were disclosed.

Grant information: Authors of this research work would like to appreciate Covenant University Management for providing sponsorship to the publication of the research in this journal.

The funders had no role in study design, data collection and analysis, decision to publish, or preparation of the manuscript.

Copyright: @ 2019 Ibidunni AS et al. This is an open access article distributed under the terms of the Creative Commons Attribution License, which permits unrestricted use, distribution, and reproduction in any medium, provided the original work is properly cited.

How to cite this article: Ibidunni AS, Olawande T, Olokundun $M$ et al. Diversity issues in Nigeria's healthcare sector: implications on organizational commitment. A cross-sectional study [version 1; peer review: 2 approved with reservations] F1000Research 2019, 8 :852 https://doi.org/10.12688/f1000research.19350.1

First published: 12 Jun 2019, 8:852 https://doi.org/10.12688/f1000research.19350.1 


\section{Introduction}

Workforce diversity has a significant impact on the work behaviour and attitudes that employees exhibit in the work environment ${ }^{1}$. Diversity of employees depicts a scenario in which different people bring their unique backgrounds, perspectives, values and benefits to the organization ${ }^{2}$.

Assessing diversity among employees is strategic to effectively managing the organization's human resources and can improve the organizational commitment and satisfaction of employees ${ }^{3}$. Furthermore, diversity in the workforce improves better decision-making, greater creativity, innovation and greater competitiveness $^{4-5}$. Workforce diversity has grown from focusing solely on human demographic characteristics; like race, gender and age, to a much broader meaning that encompasses the whole range of human, physical and cultural differences ${ }^{6}$, and this could influence their levels of job satisfaction.

In the work of $\mathrm{Jex}^{7}$, job satisfaction is described as the positive affection of an employee towards the job. According to Shuck et $a l .^{8}$, employee satisfaction itself has a direct and indirect influence on individual and organizational performance, including the commitment of employees to work. Job satisfaction, for example, is the best predictor of employee turnover. More so, having a committed workforce is important for achieving organisational performance. Therefore, it is important to produce a committed workforce that would show organisational commitment.

Today's workplace consists of different employees with unique and varied features ${ }^{9,10}$. Although, existing literature have discussed workforce components as a determinant of employee commitment ${ }^{11}$. However, the current literature does not sufficiently explained the employees feelings about diversity in their working environment, and whether diversity in the workforce results in dissatisfaction or lack of engagement, especially within the public health sector of developing economies like Nigeria. Despite that most researchers, such as Osibanjo et al. ${ }^{12}$ have been focusing on explaining concepts that enhance understanding of workforce diversity, little is understood about how workforce diversity affects employees' satisfaction and organisational commitment in the workplace. Studies on the influence of diversity in the workforce on the satisfaction of employees and the organizational commitment in the public health sector in Nigeria are rare in existing literature ${ }^{13}$. This paper therefore aims to examine the influence of diversity in the workforce on organizational commitment and employee satisfaction among selected public health workers in Nigeria, based on the following four hypotheses.

$H_{I}$ : Employee diversity significantly influences employees' affective commitment

$\mathrm{H}_{2}$ : Employee diversity significantly influences employees' continuance commitment

$H_{3}$ : Employee diversity significantly influences employees' normative commitment
$H_{4}:$ Job satisfaction moderates the relationship between workforce diversity and organizational commitment (affective, continuance and normative)

\section{Methods}

A survey method was used for data collection.

\section{Sample size and sampling procedure}

This research involved 133 public health workers from the Lagos State Ministry of Health in Nigeria and was executed between the periods of February 2017 and April 2019. This sample size was determined from a population of 200 public health workers, based on Yamane $^{14}$ sample size determination formula. Thus,

The formula

$\mathrm{n}=\mathrm{N} /\left(1+\mathrm{N}(\mathrm{e})^{2}\right)$

where

$\mathrm{n}=$ sample size

$\mathrm{e}=$ sampling error $(0.05)$

$\mathrm{N}=$ the population (that is 200 employees in the healthcare location)

$\mathrm{n}=200 /\left(1+200(0.05)^{2}\right)$

$\mathrm{n}=200 / 1+200(0.0025)$

$\mathrm{n}=200 / 1+0.5$

$\mathrm{n}=200 / 1.5$

$\mathrm{n}=133.33$ (approximately 133 )

$\mathrm{n}=133$

Public healthcare employees in Nigeria's Ministry of Health, are important for this research because of the increased awareness of the diverse workforce of the Ministry. Hence, it is imperative that such diversity is properly managed in ways that avoid negative impact on employee satisfaction and commitment to the organization ${ }^{15,16}$. Furthermore, due to the important roles that the Health sector undertake for the population and the overall well- being of any country, this research is considered essential to maintain employee interest and motivation in the provision of quality services ${ }^{17}$. Simple random sampling technique was adopted. This technique allowed every member of the population to be a respondent by selecting the respondents without any form of partiality. Thus, given the total population if public health workers in the Lagos State Ministry of Health, the 133 respondents were selected at random without any form of bias and were administered the copies of the questionnaire during working hours. Employees who turned down the proposal to participate in the survey were respectfully eliminated from the research process, and a replacement was determined by the same random selection process. The following inclusion and exclusion criteria applied: 


\section{Inclusion criteria:}

- Participants had to be employees of the organisation

- Participants must be literate, able to read and write English

- Participants must be accessible

\section{Exclusion criteria:}

- Members of casual staff

The copies of questionnaire were self-administered to respondents and retrieved within the space of eight weeks, based on the request of the respondents.

\section{Measures and variables}

Data was captured using a questionnaire developed for this study based on evidence from the literature (see extended data ${ }^{18}$ ). Workforce diversity (including gender, education, religion, ethnicity, experience, income and position) items were developed based on Glazer et al. ${ }^{19}$, work satisfaction (described as by the extent to which employees felt positive affection towards their job) items based on Jensen et al. ${ }^{20}$ were developed and workforce commitments (including affective, continuance and normative) items based on Changa et al. ${ }^{21}$ and $^{22}$ Hanaysha et al. ${ }^{22}$ were developed.

\section{Ethical consideration}

The questionnaire was administered to respondents based on their willingness to participate in the research exercise. The participants in the study were also assured of confidentiality and anonymity, such as not reflecting their names in the questionnaire. The study received verbal approval for execution as a satisfactory requirement from the organization and the employees.

\section{Validity and reliability of research instrument}

In this research, internal consistency method, using Cronbach alpha measurement was adopted to ensure reliability of the research items. It is widely accepted that the score of 0.7 above indicates the reliability of the instrument. The SPSS (Social Science Statistical Package) was used to test the reliability of the research instrument. The reliability statistics that was obtained for the instruments used for this study was 0.747. Instrument validity was ascertained through content validity.

\section{Statistical analysis}

The statistical analysis for this study was performed using SPSS software (version 22) and AMOS (version 23). The analysis of data was carried out using descriptive statistics and structural equation modelling (SEM) to show the relationships between workforce diversity, job satisfaction and organizational commitment.

\section{Results}

In terms of demographics of the respondents, 64 (48.1\%) were male while $69(51.9 \%)$ were female. The age distribution among respondents was as follows: the majority of respondents (68) were between 18 and 34 years of age, 45 respondents between 35 and 44 years of age, 13 respondents were between 45 and 54, and 7 were 55 or above years (Table 1 and underlying data $\left.^{23}\right)$.

Figure 1 shows the model for analysis of multi-variate relationships between diversity of workforce, job satisfaction and employee commitment. The statistical measurement was considered fit based on the following estimates: Chi-square / degree of freedom $(\mathrm{Cmin} / \mathrm{df})=1.603$, goodness of fit index $(\mathrm{GFI})=0.950$, normal fit index $(\mathrm{NFI})=0.892$, comparative fit index $(\mathrm{CFI})=0.952$, root mean square approximation error $($ RMSEA $)=$ 0.068 . These estimates are considered to be fit based on existing studies $^{24,25}$.

Analyses revealed varying levels of direct and mediating relationships among the research variables. Specifically, gender and ethical diversity had significant influences on job satisfaction at $\mathrm{r}=0.35(\mathrm{p}<0.05)$ and $\mathrm{r}=0.28(\mathrm{p}<0.05)$ respectively. Direct relationships were also statistically established between workforce

Table 1. Socio-demographic distribution of respondents.

\begin{tabular}{|l|l|l|l|}
\hline Demographic variable & & Frequency & Percentage \\
\hline Gender & Male & 64 & 48.1 \\
\hline \multirow{2}{*}{ Age } & Female & 69 & 51.9 \\
\hline \multirow{3}{*}{ Years of Work experience } & $18-34$ & 68 & 51.1 \\
\hline & $35-44$ & 45 & 33.8 \\
\hline & 55-54 & 13 & 9.8 \\
\hline & less than 5 years & 54 & 40.6 \\
\hline & $5-10$ years & 49 & 36.8 \\
\hline & $11-15$ years & 16 & 12.0 \\
\hline & 16 years above & 14 & 10.5 \\
\hline
\end{tabular}




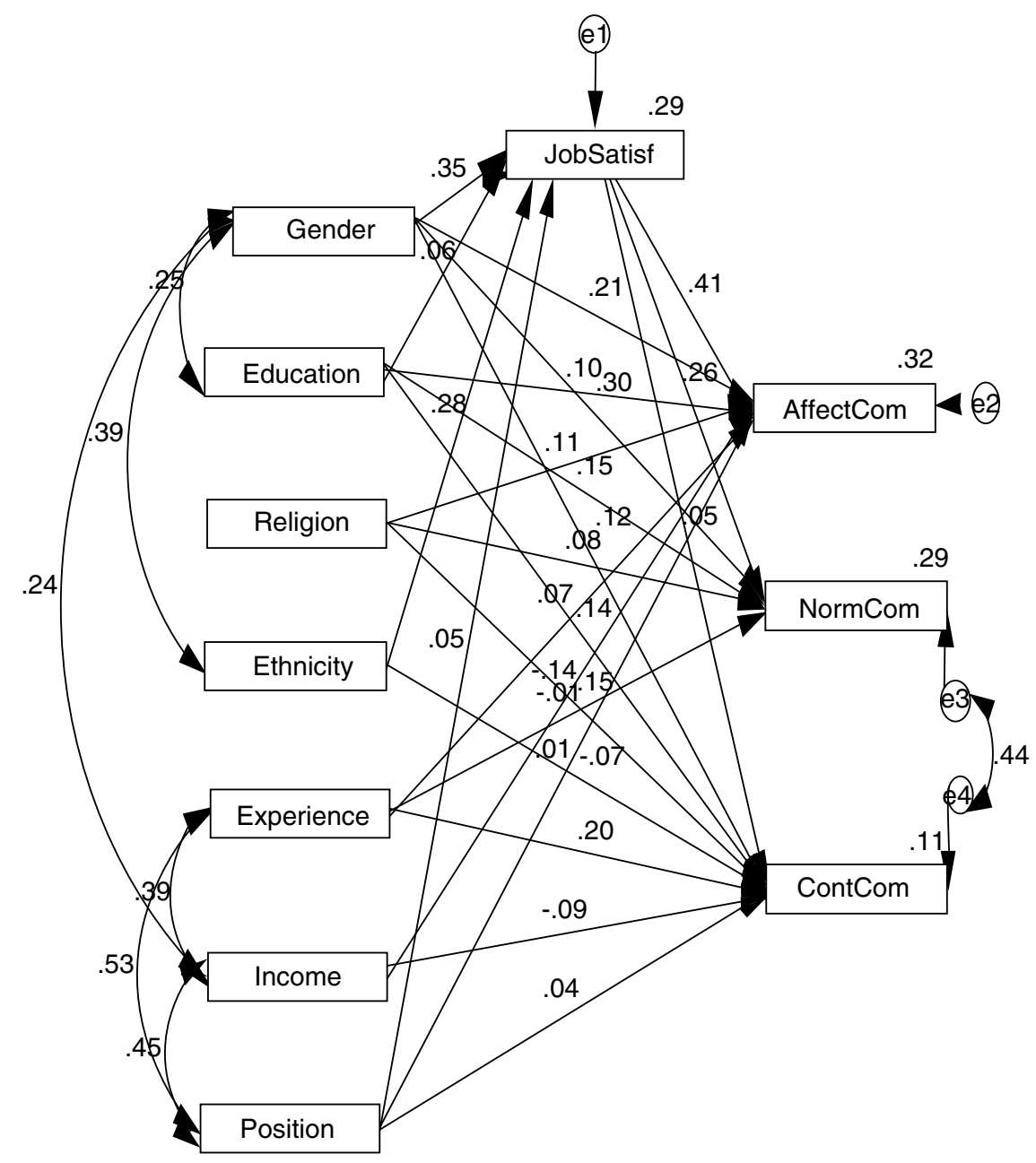

Figure 1. Regression path of workforce diversity, job satisfaction \& employee commitment.

diversity and organizational commitment in the following ways: gender diversity and affective commitment $(r=0.26$, $\mathrm{p}<0.05)$, normative commitment $(\mathrm{r}=0.05, \mathrm{p}<0.05)$; education diversity and normative commitment $(\mathrm{r}=0.12)$; experience diversity and continuance commitment $(\mathrm{r}=0.20, \mathrm{p}<0.05)$. A direct inverse relationship was established between religion diversity and continuance commitment $(\mathrm{r}=-0.14, \mathrm{p}<0.05)$. The following mediating relationships were also statistically confirmed: job satisfaction related with affective commitment $(\mathrm{r}=0.41, \mathrm{p}<0.05)$ and normative commitment $(\mathrm{r}=0.26$, $\mathrm{p}<0.05)$. The results of these data support existing research results $^{21,26}$.

\section{Discussion and Conclusion}

Researchers like Ashikali et al. ${ }^{27}$, Ibidunni et al. ${ }^{26}$ and Hanaysha et $a .^{28}$ demonstrated that diversity in the workforce promotes creativity, innovative problem solving and productivity. Also, Moon $^{28}$ confirmed that large organizations use various teams intentionally to solve problems and employed people from a diversity races, ethnicities and experience to shape perspectives in the organization ${ }^{29,30}$.
Although arguments for diversity are naturally attractive and somewhat popular, there is little empirical evidence that diversity in the workforce can be used to increase employee engagement, especially in developing economies such as Nigeria. Whether employee diversity influences organizational engagement is an empirical issue that has not been properly tested in Nigeria in the public sector context. This study therefore contains evidence to fill this gap. The results of this study show that gender is the most sensitive factor in the diversity that influences Nigeria's commitment to public health workers. Gender diversity is associated with the affective and normative aspects of the commitment of employees ${ }^{31,32}$. These two dimensions of commitment reflect the degree to which employees are emotionally committed to their productivity at work ${ }^{26,33}$. The promotion of gender equality at work must therefore be seen as a strategic way to increase the commitment of public health workers in Nigeria.

Our results demonstrate that the diversity of the workforce has a significant impact on the satisfaction and commitment of Nigerian public health professionals. Based on the results 
of the statistical analysis, the study concludes that there is a relationship between diversity of employees and job satisfaction, diversity of employees and organizational commitment and the influence of work satisfaction on organizational commitment. Therefore, this study has important implications for directing policymakers to ensure that the demographic diversity among public health workers is treated as a strategic part of employee selection. This in turn significantly influences their levels of job satisfaction and commitment to the organization.

\section{Data availability}

\section{Underlying data}

Figshare: ADELEKAN SPSS.sav, https://doi.org/10.6084/ m9.figshare.8144498.v123

This project contains the following underlying data:

- ADELEKAN SPSS.sav (SPSS spreadsheet of primary data collected to establish the relationships between workforce diversity, job satisfaction and organisational commitment of public health workers in Lagos state, Nigeria)

\section{Extended data}

Figshare: Questionnaire. https://doi.org/10.6084/ m9.figshare.8144564.v1 $1^{18}$

This project contains the following extended data:

- RESEARCH QUESTIONNAIRE.pdf (Study questionnaire)

Data are available under the terms of the Creative Commons Zero "No rights reserved" data waiver (CC0 1.0 Public domain dedication).

Grant information

Authors of this research work would like to appreciate Covenant University Management for providing sponsorship to the publication of the research in this journal.

The funders had no role in study design, data collection and analysis, decision to publish, or preparation of the manuscript.
1. McKay PF, Avery DR, Morris MA: Mean Racial-Ethnic Differences In Employee Sales Performance: The Moderating Role Of Diversity Climate. Pers Psychol. 2008; 61(2): 349-374.

Publisher Full Text

2. Otike W, Messah B, Mwaleka K: Effects of Workforce Diversity on Organizational Effectiveness: A Case Study On Kenya Commercial Bank Ltd. Journal Of Business And Management. 2010. Reference Source

3. Black \& Enterprise: "Managing a multicultural workforce. Black Enterprise Magazine (July).Canada", Equal Opportunities International. 2001; 15(5): 1-27.

4. Gupta R: Workforce Diversity and Organizational Performance. International Journal of Business Management Invention. 2013; 2(6): 36-44. Reference Source

5. Daft RL, Kendrick M, Natalia V: Management. Hampshire: South Western Cengage Learning. 2010.

Reference Source

6. Jayne M, Dipboye R: Leveraging diversity to improve business performance: Research findings and recommendations for organizations. J Hum Resour Manag. 2004; 43(4): 409-424.

Publisher Full Text

7. Jex SM: Organizational psychology: A scientist-practitioner approach. New York, NY:John Wiley \& Sons, Inc. 2002. Reference Source

8. Shuck B, Collins JC, Rocco TS, et al: Deconstructing the Privilege and Power of Employee Engagement: Issues of Inequality for Management and Human Resource Development. Hum Resour Dev Rev. 2016; 15(2): 208-229. Publisher Full Text

9. Goby VP, Nickerson C, David E: Interpersonal communication and diversity climate: promoting workforce localization in the UAE. Int J Organ Anal. 2015; 23(3): 364-377.

Publisher Full Text

10. Singh SK: Territoriality, task performance, and workplace deviance: Empirical evidence on role of knowledge hiding. J Bus Res. 2019; 97: 10-19. Publisher Full Text

11. Schilpzand P, De Pater IE, Erez A: Workplace incivility: A review of the literature and agenda for future research. J Organ Behav. 2016; 37(S1): 57-88. Publisher Full Text

12. Osibanjo AO, Abiodun AJ, Adeniji AA: Impact of job environment on job satisfaction \& commitment among Nigerian nurses. Proceedings of the 22nd International Business Information Management Association Conference, 2013; 3 . 1743-1752.

Reference Source

13. Watson WE, Johnson L, Zgourides GD: The influence of ethnic diversity on leadership, group process, and performance: An examination of learning teams. Int J Intercult Relat. 2002; 26(1): 1-16. Publisher Full Text

14. Yamane T: Statistics, An Introductory Analysis. 2nd Ed., New York: Harper and Row. 1967. Reference Source

15. Abiodun AJ, Ibidunni AS, Kehinde OJ: Demographic Determinants of Communication and Information Technology Appreciation and Usage among Health Care Professionals. Int J Health Econ. 2015; (5): 5-19. Reference Source

16. Falola HO, Olokundun MA, Salau OP, et al:: Data article on the effect of work engagement strategies on faculty staff behavioural outcomes in private universities. Data Brief. 2018; 18: 1383-1387. Publisher Full Text

17. Ayeni AW, Iyiola OO, Ogunnaike OO, et al:: Globalisation and Ebola disease: Implications for business activities in Nigeria. Afr J Bus Manage. 2017; 11(3): 47-56. Publisher Full Text

18. Ibidunni AS: Questionnaire. figshare. Online resource. 2019 http://www.doi.org/10.6084/m9.figshare.8144564.v1

19. Glazer G, Tobias B, Mentzel T: Increasing healthcare workforce diversity: Urban universities as catalysts for change. J Prof Nurs. 2018; 34(4): 239-244. PubMed Abstract | Publisher Full Text | Free Full Text

20. Jensen KW, Liu Y, Schøtt T: Entrepreneurs' innovation bringing job satisfaction, work-family balance, and life satisfaction: In China and around the world. Int $J$ Innov Stud. 2017; 1(4): 193-206. Publisher Full Text

21. Changa $\mathrm{E}$, Chinb H: Signaling or experiencing: Commitment HRM effects on recruitment and employees' online ratings. J Bus Res. 2018; 84: 175-185. Publisher Full Text

22. Hanaysha J: Examining the Effects of Employee Empowerment, Teamwork, and Employee Training on Organizational Commitment. Procedia Soc Behav Sci. 2016; 229: 298-306. Publisher Full Text

23. Ibidunni AS: ADELEKAN SPSS.sav. figshare. Dataset. 2019 http://www.doi.org/10.6084/m9.figshare.8144498.v1

24. Hipp JR, Bollen KA: Model Fit in Structural Equation Models with Censored, Ordinal, and Dichotomous variables: Testing Vanishing Tetrads. Sociol Methodol. 2003; 33: 267-305 Publisher Full Text

25. Schumacker RE, Lomax RG: A beginner's guide to structural equation modelling. (3rd ed.). New York: Routledge. 2010. Reference Source 
26

Ibidunni AS, Falola HO, Ibidunni OM, et al:: Workforce diversity among public healthcare workers in Nigeria: Implications on job satisfaction and organisational commitment. Data Brief. 2018; 18: 1047-1053.

PubMed Abstract | Publisher Full Text | Free Full Text

27. Ashikali T, Groeneveld S: Diversity Management in Public Organizations and Its Effect on Employees' Affective Commitment: The Role of Transformationa Leadership and the Inclusiveness of the Organizational Culture. Rev Public Pers Adm. 2015; 35(2): 146-168.

Publisher Full Text

28. Moon KK: Examining the Relationships Between Diversity and Work Behaviors in U.S. Federal Agencies: Does Inclusive Management Make a Difference? Re Public Pers Adm. 2018; 38(2): 218-247.

Publisher Full Text

29. Bransford JD, Brown AL, Cocking RR, (Eds): How people learn: Brain, Mind,
Experience and School. Washington D.C: National Academy Press. 2000 Publisher Full Text

30. Kreitner R, Kinichi A: Organizational Behaviour. Boston: McGraw-Hill. 2004. Reference Source

31. Choi S: Workforce Diversity and Job Satisfaction of the Majority and the Minority: Analyzing the Asymmetrical Effects of Relational Demography on Whites and Racial/ Ethnic Minorities. Rev Public Pers Adm. 2017; 37(1): 84-107. Publisher Full Text

32. Oyinlade AO: Relations of Job Structure to Affective Organizational Commitment. J Hum Resour Manag Labor Stud. 2018; 6(1): 13-32. Reference Source

33. Messner W: The role of gender in building organisational commitment in India's services sourcing industry. IIMB Management Review. 2017; 29(3): 188-202. Publisher Full Text 


\section{Open Peer Review}

\section{Current Peer Review Status: ? ?}

\section{Version 1}

Reviewer Report 21 January 2021

https://doi.org/10.5256/f1000research.21210.r74647

(C) 2021 Lee J. This is an open access peer review report distributed under the terms of the Creative Commons Attribution License, which permits unrestricted use, distribution, and reproduction in any medium, provided the original work is properly cited.

\section{? Joonghak Lee}

Department of International Business and Strategy, University of Reading, Reading, UK

Thanks for your interesting article.

I have a few comments on your literature review and method:

First, it would be much better cite recent diversity articles. Also, there should be more studies about the relationship between dependent variables and independent variables.

Second, even if you use cross-sectional data, you don't mention anything about its limitation such as the Common Method bias. The authors should try to analyze CFA or Harman's single factor analysis to minimize reviewer's concern.

Is the work clearly and accurately presented and does it cite the current literature? Partly

Is the study design appropriate and is the work technically sound?

Yes

Are sufficient details of methods and analysis provided to allow replication by others? Yes

If applicable, is the statistical analysis and its interpretation appropriate? Partly

Are all the source data underlying the results available to ensure full reproducibility? Yes

Are the conclusions drawn adequately supported by the results?

Yes 
Competing Interests: No competing interests were disclosed.

I confirm that I have read this submission and believe that I have an appropriate level of expertise to confirm that it is of an acceptable scientific standard, however I have significant reservations, as outlined above.

Reviewer Report 19 January 2021

https://doi.org/10.5256/f1000research.21210.r77553

(C) 2021 Inegbedion $\mathbf{H}$. This is an open access peer review report distributed under the terms of the Creative Commons Attribution License, which permits unrestricted use, distribution, and reproduction in any medium, provided the original work is properly cited.

\section{Henry Inegbedion}

Department of Business Studies, Landmark University, Omu Aran, Nigeria

The research problem is very relevant and timely, given the challenges of the health sector globally amidst the COVID-19 pandemic. The authors did well to articulate the problem convincingly. However, there are some issues that require adequate attention in order to enhance the quality of the paper:

1. The article needs to be thoroughly edited to take care of the grammatical errors.

2. The paper is not underpinned by any theory. This is a significant omission since some of the underlying concepts in the research problem have theoretical basis that can be usefully employed.

3. The authors did not develop the hypotheses formulated. How did they come about the hypotheses? The absence of hypotheses development is a consequence of the weak empirical review.

4. The methodology section is good but the authors need to indicate the basis of randomization in sample selection as well as how content validity was employed in the validation of the research instrument. Lastly, they should justify the application of the structural equation model, provide a mathematical formulation of the model and segregate the measurement model from the latent component.

5. In the interpretation of results, the authors should check gender diversity and normative commitment $(r=0.05, p<0.05)$ as well as the statement: "A direct inverse relationship was established between religion diversity and continuance commitment".

Is the work clearly and accurately presented and does it cite the current literature? Partly

Is the study design appropriate and is the work technically sound? 
Are sufficient details of methods and analysis provided to allow replication by others? Partly

If applicable, is the statistical analysis and its interpretation appropriate? Yes

Are all the source data underlying the results available to ensure full reproducibility? Yes

Are the conclusions drawn adequately supported by the results? Partly

Competing Interests: No competing interests were disclosed.

Reviewer Expertise: Operations Management, Quantitative Analysis, Marketing and Financial Economics

I confirm that I have read this submission and believe that I have an appropriate level of expertise to confirm that it is of an acceptable scientific standard, however I have significant reservations, as outlined above.

The benefits of publishing with F1000Research:

- Your article is published within days, with no editorial bias

- You can publish traditional articles, null/negative results, case reports, data notes and more

- The peer review process is transparent and collaborative

- Your article is indexed in PubMed after passing peer review

- Dedicated customer support at every stage

For pre-submission enquiries, contact research@f1000.com 